\title{
Influence of the Hydrogel Amendment on the Water Retention Capacity of Extensive Green Roof Models
}

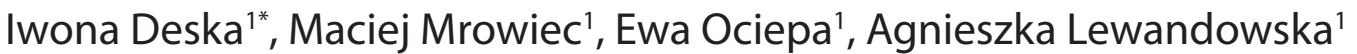 \\ 1 Faculty of Infrastructure and Environment, Czestochowa University of Technology, Brzeźnicka 60A, \\ 42-215 Częstochowa, Poland \\ * Corresponding author's e-mail: ideska@is.pcz.czest.pl
}

\begin{abstract}
The goal of the research was to investigate the retention capacity of six green roof models (SHP1, SHP2, SHP3, $\mathrm{SH}, \mathrm{S}$, and SP) constructed with the use of the square-shaped plastic trays, Floradrain FD 25 drainage elements, SF filter sheets, and the specified extensive substrates (with or without the hydrogel amendment). The SHP1 and SHP2 models were constructed in March 2017, SHP3 and SH - in November 2017, while S and SP - in April 2018. Four models (SHP1, SHP2, SHP3, and SP) contained the plants (the goldmoss stonecrop Sedum Acre), whereas two models ( $\mathrm{S}$ and $\mathrm{SH}$ ) did not contain the vegetation. The substrates of SHP1, SHP2, SHP3, and SH models contained the hydrogel admixtures. The investigations were conducted with the use of simulated (and partially natural) precipitations. The water retention capacity of each green roof model was established based on the difference between the precipitation volume and the volume of runoff from a model. The results show that green roofs can be useful stormwater management tools. The calculated stormwater retention rates ranged from $29.50 \%$ to $85.15 \%$. In most cases, the best water retention capacity was exhibited by the SHP3 model, constructed in November 2017 and planted in April 2018, containing the substrate amended with superabsorbent (cross-linked potassium polyacrylate). The similarly constructed SHP1 and SHP2 models, which were built in March 2017, in some cases had lower water retention capacity. These models contained older hydrogel and were overgrown with older, smaller, and worse looking plants, partially supplanted by mosses. Such results indicate that the efficiency of hydrogel may decrease over time. In many cases, the S (not vegetated, without hydrogel), SH (not vegetated, with substrate containing hydrogel), and SP (vegetated, without hydrogel) models had slightly lower water retention capacity. The results of investigations indicate that there was a relatively strong positive linear correlation between the retention depth and duration of the antecedent period elapsed from the preceding total (or substantial) saturation of the green roof models (labelled in this article as period since total saturation - PSTS). The weather conditions i.e. air temperature and relative humidity as well as PSTS are very important parameters that influence the retention capacity of the green roof models. The result show that duration of PSTS can be stronger correlated with the retention depth than antecedent dry period (ADP) elapsed from the end of last precipitation, regardless of its depth and intensity.
\end{abstract}

Keywords: green roof, retention capacity, stormwater management, substrate, superabsorbent polymer, hydrogel

\section{INTRODUCTION}

The progress of urbanization as well as the population growth lead to the continuous expansion of space and density of urban areas, thereby resulting in an increased amount of sealed surfaces, especially in great cities. Thus, the natural areas - forests, grasslands etc. are replaced by impervious surfaces, e.g.: streets, buildings, and squares [Mentens et al., 2006]. The persistent sealing of land surface can cause a lot of consequences for infrastructure in the cities and surrounding environment, e.g. it leads to a decreased stormwater infiltration, thus increasing the surface runoff intensity [Czemiel-Berndtsson, 2010; Burszta-Adamiak, 2012]. Additionally, the climate changes progressing due to high population growth and technological development may cause an increase of the frequency, intensity and duration of the extreme rainfall events [Mrowiec et al., 
2018; Ramos et al., 2017]. Both the urbanization and climate changes transform the natural hydrological processes in the catchments and increase the threat of flooding [Jato-Espino et al., 2016]. In this regard, there is a need for application of Sustainable Urban Drainage Systems (SUDS) that can support the operation of conventional drainage systems, especially in urban areas. SUDS can be used with traditional sewage systems to optimize them and allow greater control over quantity and quality of stormwater [Ramos et al., 2017]. The major objective of using SUDS is replicating the natural drainage of the rainwater in the urban catchments as closely as possible [Fletcher et al., 2017; USEPA, 2007]. They include, inter alia, permeable pavements, stormwater drainage wells, geocellular storage systems [Jato-Espino et al., 2016; Erickson et al., 2018; Aung et al., 2016; Edwards et al., 2016], bioretention systems (such as rain gardens), and green roofs [CzemielBerndtsson et al., 2009].

Green roofs are the layered constructions installed on roofs of buildings, which are covered with growing media (substrates) and vegetation. They compensate the related impervious areas of the buildings and can play an important role in the stormwater management. These constructions are divided into intensive, simple intensive (semiintensive), and extensive [Czemiel-Berndtsson et al., 2009; Ramos et al., 2017]. The extensive green roofs are much more common than the intensive and semi-intensive roofs due to costs and the building weight restrictions [Getter and Rowe, 2006]. The typical plants overgrowing the extensive green roofs should be extremely sun and drought tolerant (e.g. succulents, grasses, herbs, mosses etc.) [Czemiel-Berndtsson et al., 2009; Grant, 2006].

Extensive green roofs provide numerous ecological and economic benefits, but one of their most important functions is the mitigation of the stormwater runoff [VanWoert et al., 2005]. They reduce the intensity of the stormwater runoff primarily due to the evapotranspiration [CzemielBerndtsson et al., 2006]. The hydrologic performance of green roofs can be usually assessed in terms of stormwater retention rate or stormwater retention capacity. Stormwater retention rate can be expressed as the percentage of precipitation retained by the green roof layers during a rainfall event. The stormwater retention capacity can be estimated based on the maximum volume of water (or depth of precipitation) that can be retained within green roof layers under certain conditions [Akther et al., 2018]. The water retention capacity, as well as retention rate of green roofs are influenced, among others, by climatic conditions (e.g. temperature and relative humidity of air), the roof type (intensive, semiintensive, extensive), the green roof slope, the thickness and composition of substrate, the type and construction of drainage elements, the length of antecedent dry period, etc. [Mentens et al., 2006; Akther et al., 2018; Getter et al., 2007].

Substrate is one of the most important elements of green roof. It plays a crucial role in the vegetation growth. It supplies water and essential nutrients to plants, guarantees the stability of plants and has capacity to maintain the physical, chemical, and biological conditions for vegetative development [Young et al., 2014; Cascone, 2019]. The substrates should be well-permeable for both water and air. High water permeability allows the rapid infiltration of rainwater from the growing medium surface to deeper layers of green roof, while diminishing the surface runoff and substrate erosion [Akther et al., 2018]. High porosity and the subsequent good air permeability influences good plant roots ventilation, thus preventing their rotting [Young et al., 2014].

In summer, during hot and dry weather, the growing medium is exposed to drought due to relatively small thickness and low water capacity. The availability of water for plants can be increased through use of various substrate amendments which help plants to survive the adverse weather conditions [Farrell et al., 2013]. One of such amendments can by superabsorbent polymers (SAPs), also referred to as hydrogels that can play a role of "artificial humus" in the growing medium [Farrell et al., 2013, Savi et al., 2014; Hüttermann et al., 2009]. SAPs can absorb considerable amounts of water (up to several hundred times more than their dry mass) [Lejcuś et al., 2018]. Young et al. found that the amendment of substrate with hydrogel can improve its water holding capacity and may be useful at providing water to plants during a drought stress [Young et al., 2014]. It can be very important especially in the case of newly created green roofs, when young plants are poorly rooted.

The goal of research described in the paper was to investigate the influence of the vegetation and the addition of the hydrogel to the substrate on the water retention capacity of six green roof models. 


\section{MATERIALS AND METHODS}

The research was conducted in Częstochowa (at the Institute of Environmental Engineering, ul. Brzeźnicka 60A) from 25/03/2019 to 28/06/2019 under natural weather conditions. The investigations were carried out with use of 6 green roof models constructed on the square-shaped $(60 \times 60 \mathrm{~cm})$ plastic garden trays (Figure 1).

A hole was drilled in the right lower corner of each tray and a plastic flexible PVC hose was installed in order to enable the outflow of excess water from the layers of green roof model. The following components were placed on the bottom of each tray: Floradrain FD 25 drainage element (docked for the internal tray dimensions at the bottom, which amounted to about $55.7 \times 55.7$ ), SF filter sheet $(70 \times 70 \mathrm{~cm})$, extensive substrate (with or without the hydrogel amendment) and the plants (in the case of 4 models). The average area of substrate surface in the case of each model amounted to $3213.3 \pm 17.2 \mathrm{~cm}^{2}$, and the average thickness of substrate amounted to about $32 \pm 1 \mathrm{~mm}$. The slope of model bottoms (in two perpendicular directions) amounted to about 5\%. The cross-sections of models are presented in Figure 2.

The SHP1 and SHP2 models were constructed in March 2017, SHP3 and SH - in November
2017, and S and SP - in April 2018. The substrates of SHP1, SHP2, SHP3, and SH models contained the hydrogel admixture. They were built of two layers. The lower layers consisted of the "Sedum Carpet" extensive substrate with $0.5 \%$ admixture (by weight) of the cross-linked potassium polyacrylate and the upper layers consisted of the above-mentioned substrate without any additional amendments. The S and SP models contained the uniform layers of "Sedum Carpet" substrate without any amendments. Four models (SHP1, SHP2, SHP3, and SP) contained the vegetation (the goldmoss stonecrop Sedum Acre), whereas two models (S and $\mathrm{SH}$ ) did not contain plants. The sedum on the SHP1 model was planted in March 2017, while the sedum on the SHP2 model was sieved from seeds in August 2017. The sedum on the SP and SHP3 models was planted in April 2018. The investigations were conducted with the use of simulated and natural precipitations. The water retention capacity of green roof models was established on the basis of the differences between the volumes of precipitations (simulated or natural) and the volumes of runoff from models. The parameters of natural precipitations and the atmospheric conditions prevailing during investigations were recorded using the weather station Vantage Pro2 (Davis Instruments, Hayward, USA) at 10-minute time intervals.

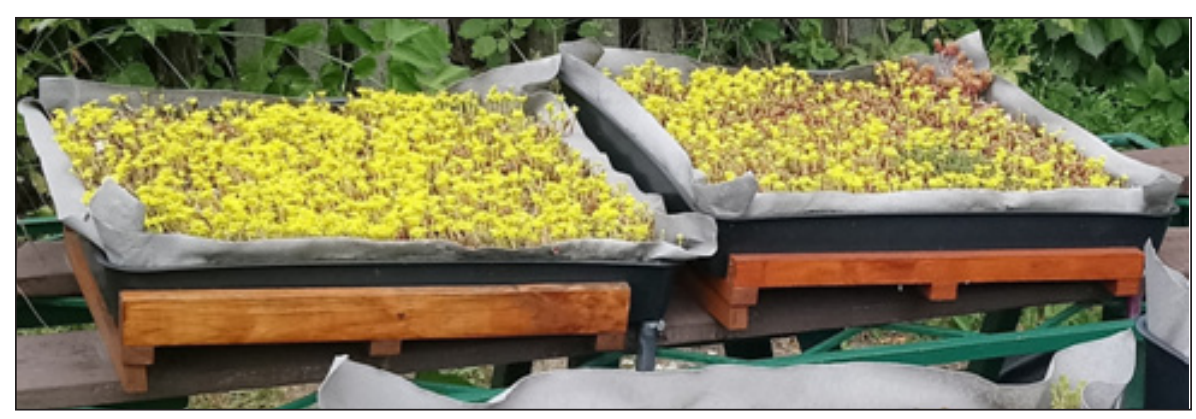

Figure 1. The green roof models SHP1 and SHP2

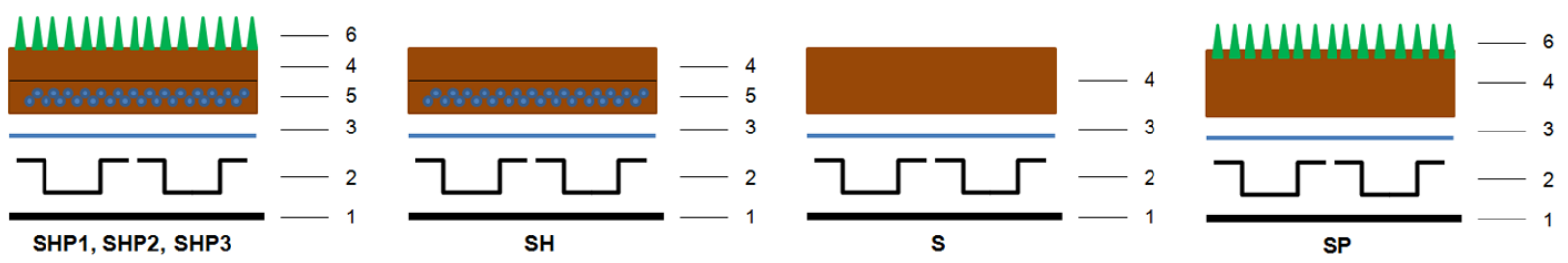

Figure 2. Cross-sections of the green roof models: 1 - garden tray bottom, 2 - Floradrain drainage element, 3 -SF filter sheet, 4 - the "Sedum carpet" extensive substrate without additions, 5 - the "Sedum carpet" substrate containing $0.5 \%$ by weight of potassium polyacrylate, 6 - the plants 


\section{RESULTS AND DISCUSSION}

Table 1 presents the selected parameters of simulated precipitations and the averaged atmospheric conditions prevailing during antecedent dry periods (ADP) and antecedent periods elapsed from preceding total (or substantial) saturation of green roof models (in this article abbreviated as PSTS). It should be noted that ADP is in this case the duration of period elapsed from the end of preceding rain, regardless of its intensity and PSTS (that can be equal to ADP or longer) is duration of period elapsed from the end of precipitation with sufficient depth that caused runoff or at least led to total or considerable saturation of all green roof layers. The data presented in Table 1 show that in the case of 5 simulated rains, PSTS was longer than ADP. In the case of artificial (simulated) precipitations analysed in this article, the rain depths were calculated based on the volumes of water irrigated on the substrate surface of each model and the average substrate surface that amounted to $3213.3 \pm 17.2 \mathrm{~cm}^{2}$. The depths of the natural rains occurring during investigations as well as air temperature and relative humidity prevailing during the research period were recorded using the weather station Vantage Pro2.

The values of air temperature $(T)$ and relative humidity $(R H)$ prevailing during the experiments are shown in the box-whisker plots presented in Figures 3 and 4, respectively. These plots show how the values in the data of both daily $T$ (in ${ }^{\circ} \mathrm{C}$ ) and $R H$ (in \%) are spread out.

Figure 5 presents the volumes of rainwater retained within the layers of green roof models during the rainfall events. In two cases, the combined precipitations (simulated + natural) were used because it was not possible to precisely separate the runoffs after these rainfalls. The share of artificial precipitation in the rainfalls simulated in the days 25/03/2019-26/03/2019 and $21 / 05 / 2019-23 / 05 / 2019$ amounted to $98.5 \%$ and $37.2 \%$, respectively. Table 2 presents the results of stormwater retention rate calculated as a ratio of volume of rainwater retained within individual green roof model and the volume of the rainfall.

The results presented in both Figure 5 and Table 2 show that green roofs can reduce the stormwater runoff, and thus, can support the traditional sewage systems. The stormwater retention rate (the reduction of the stormwater runoff) in the case of the tested models ranged from $29.50 \%$ (rain simulated on 16/05/2019 - Model S) to $85.15 \%$ (rain simulated on 28/06/2019 - Model SHP1). Generally, the depth of precipitation event influences rainfall retention rate expressed as the percentage of rainfall retained within green roofs. In their research Gong et al. reported an investigation conducted in Beijing for 22 rainfall events with use of 10 green roof modules in which lower values of stormwater retention rate were obtained in the case of heavy rains, while high retention rates were observed in the case of small storms [Gong et al., 2018]. Similar results were obtained by Burszta-Adamiak in the research conducted in Wrocław. In her work, generally the highest retention rates were obtained during small rainfalls (with depth less than $1 \mathrm{~mm}$ ) [Burszta-Adamiak, 2012]. In the current research, such an analysis was not possible because 6 from 8 precipitations had almost the same depth amounting to $15.6 \pm 0.2 \mathrm{~mm}$ (or $15.8 \pm 0.4 \mathrm{~mm}$ ). On the other hand, the rain simulated on 16/05/2019 had low depth $(6.2 \pm 0.1 \mathrm{~mm})$ because a relatively low value of retention capacity was expected due to short ADP (equal in this case to PSTS). It should

Table 1. Parameters of precipitations and atmospheric conditions prevailing during antecedent dry periods ( $\mathrm{s}$ - simulated, $\mathrm{n}$ - natural, $T_{m}$ - mean temperature, $R H_{m}-$ mean relative humidity)

\begin{tabular}{|c|c|c|c|c|c|c|c|c|c|}
\hline \multirow[t]{2}{*}{ Date } & \multirow[t]{2}{*}{$\begin{array}{l}\text { Rain } \\
\text { type }\end{array}$} & $\begin{array}{c}\text { Rain } \\
\text { volume }\end{array}$ & $\begin{array}{l}\text { Rain } \\
\text { depth }\end{array}$ & ADP & $\begin{array}{c}T_{m} \text { during } \\
\text { ADP }\end{array}$ & $\begin{array}{c}\mathrm{RH}_{m} \\
\text { during } \\
\mathrm{ADP}\end{array}$ & PSTS & $\begin{array}{c}T_{m} \text { during } \\
\text { PSTS }\end{array}$ & $\begin{array}{c}\mathrm{RH}_{m} \\
\text { during } \\
\text { PSTS }\end{array}$ \\
\hline & & {$\left[\mathrm{cm}^{3}\right]$} & {$[\mathrm{mm}]$} & [d:h:min] & {$\left[{ }^{\circ} \mathrm{C}\right]$} & {$[\%]$} & [d:h:min] & {$\left[{ }^{\circ} \mathrm{C}\right]$} & {$[\%]$} \\
\hline 25/03/2019-26/03/2019 & $s+n$ & $5077 \pm 102$ & $15.8 \pm 0.4$ & $1: 22: 50$ & 9.9 & 64.9 & $6: 23: 10$ & 7.2 & 72.3 \\
\hline 01/04/2019 & s & $5000 \pm 25$ & $15.6 \pm 0.2$ & $5: 15: 10$ & 7.1 & 72.9 & $5: 15: 10$ & 7.1 & 72.9 \\
\hline 08/04/2019 & S & $5000 \pm 25$ & $15.6 \pm 0.2$ & $1: 16: 10$ & 10.3 & 79.4 & 7:00:00 & 11.0 & 58.6 \\
\hline $15 / 04 / 2019$ & s & $5000 \pm 25$ & $15.6 \pm 0.2$ & $1: 15: 50$ & 7.0 & 51.6 & $6: 10: 30$ & 6.5 & 66.0 \\
\hline $16 / 05 / 2019$ & s & $2000 \pm 10$ & $6.2 \pm 0.1$ & $0: 05: 40$ & 9.6 & 96.7 & $0: 05: 40$ & 9.6 & 96.7 \\
\hline 21/05/2019-23/05/2019 & $s+n$ & $8074 \pm 169$ & $22.2 \pm 0.5$ & 0:04:00 & 15.3 & 82.2 & $3: 12: 20$ & 17.3 & 75.0 \\
\hline 04/06/2019 & s & $5000 \pm 25$ & $15.6 \pm 0.3$ & $1: 18: 20$ & 21.4 & 65.0 & 6:03:10 & 18.2 & 67.4 \\
\hline 28/06/2019 & s & $5000 \pm 25$ & $15.6 \pm 0.3$ & $6: 17: 10$ & 23.3 & 62.5 & $6: 17: 10$ & 23.3 & 62.5 \\
\hline
\end{tabular}



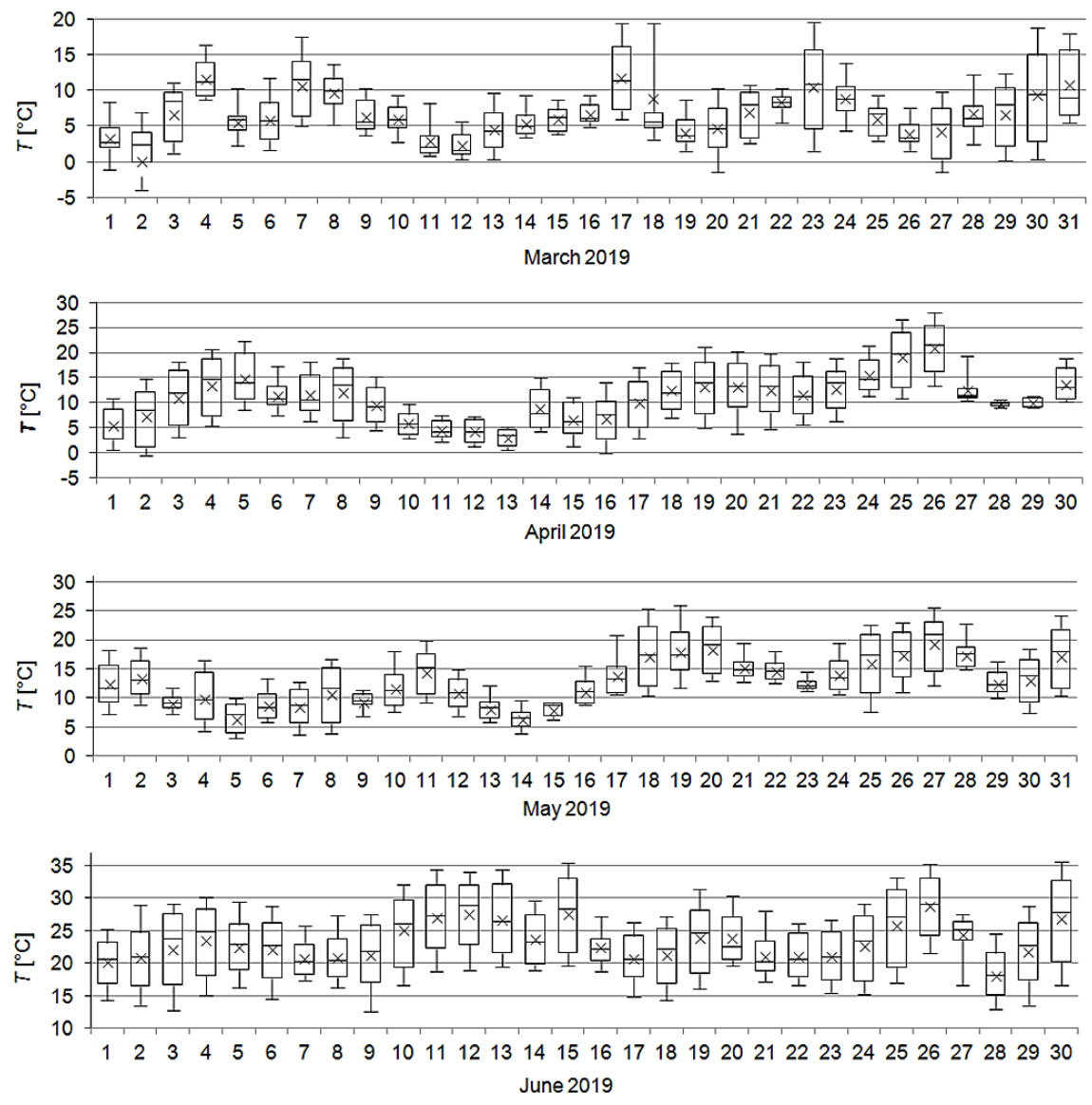

Figure 3. The values of air temperature prevailing during investigations: $\times-$ mean daily air temperature

be mentioned that in the case of the models containing plants and hydrogel the lowest stormwater retention rates were obtained during the combined rain with the highest depth that occurred on 21/05/2019-23/05/2019. During this rain, especially on $23 / 05 / 2019$, the air temperature was relatively low and relative humidity was very high (near 95\%) (see Figures 3 and 4). It cannot be excluded that in this case the water vapour additionally condensed on the plant surfaces.

The results presented in Figure 5 indicate that in most cases the best retention capacity (expressed as the volume of rainwater retained within model of green roof) was exhibited by the SHP3 model, constructed in November 2017 and planted in April 2018, with substrate amended with superabsorbent. In the case of SHP3, the retention rate amounted to $69.35 \%$ (considering 8 rain events). The total depth of rainfall retained within the SHP3 model (referred to as retention depth) amounted to $74.46 \mathrm{~mm}$.

The remaining similar constructed models which were built in March 2017 (SHP1 and SHP2), containing older, smaller, and weaker plants partially supplanted by mosses, in some cases retained slightly smaller amounts of rainwater than the SHP3 model. On the basis of the results presented in both Figure 5 and Table 2, it should be stated that the S (not vegetated, with substrate without additions), SH (not vegetated, with substrate containing hydrogel), and SP (vegetated, with substrate without hydrogel amendment) models had lower water retention capacity than the models containing both plants and hydrogel (SHP1, SHP2, and SHP3). The results indicate that in some cases hydrogel can have a positive effect on the water retention capacity of green roofs but its effectiveness is probably additionally affected by the presence and health of plants. On the basis of the results, it can be concluded that the efficacy of hydrogel decreased over time, among others due to its decay under the influence of solar radiation. Savi et al. in their work also reported the decrease in water holding capacity of the substrate containing hydrogel, observed 5 months after the establishment of the green roof modules [Savi et al., 2014]. It can be concluded that the addition of hydrogel into the growing medium can have a positive effect on the retention capacity of vegetated roof, but the 

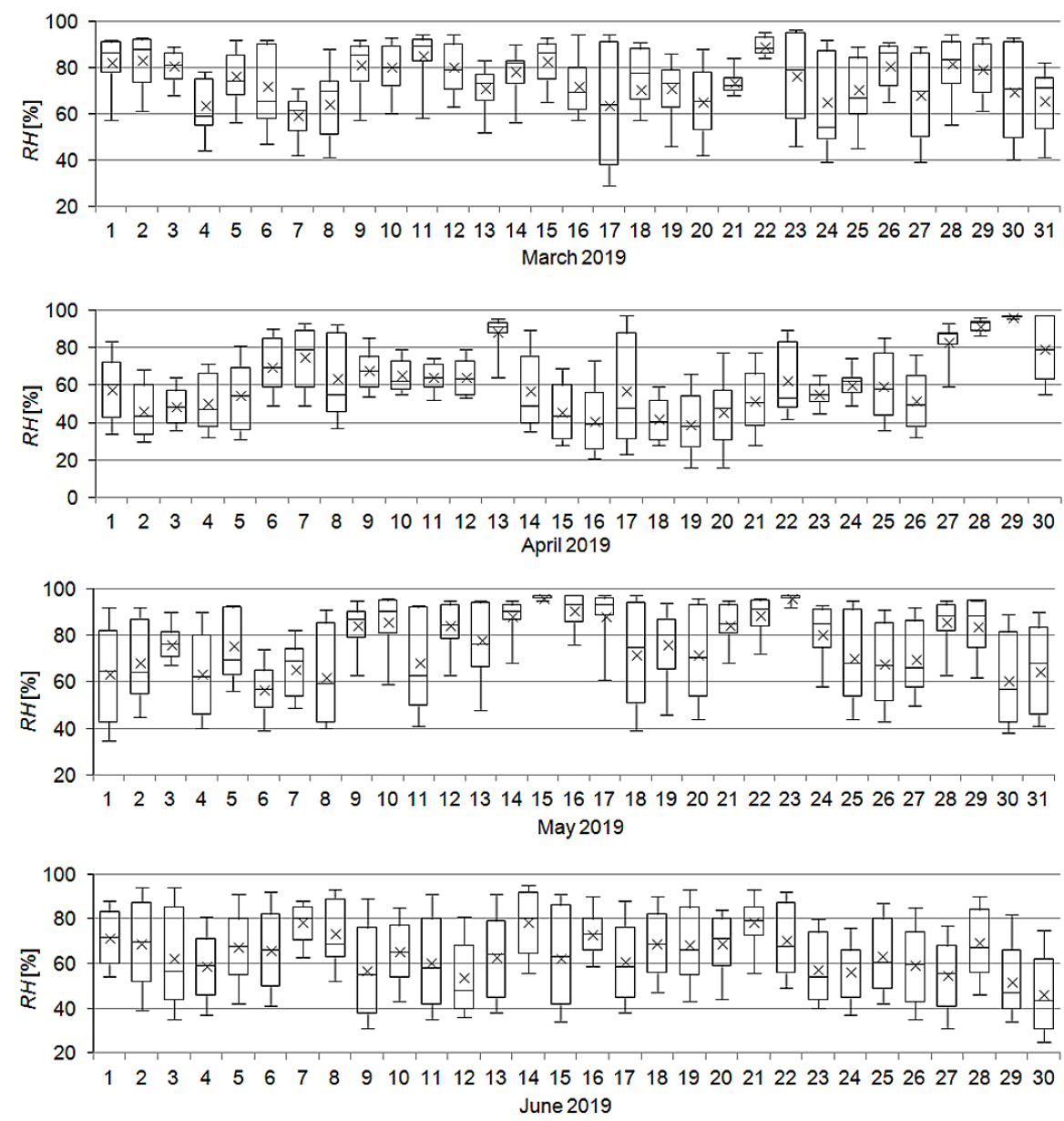

Figure 4. The values of relative humidity of air prevailing during investigations: $x-$ mean daily relative humidity

efficiency of hydrogel may decrease over time, i.a. due to its decay under the influence of solar radiation. However, the use of superabsorbent polymers may allow plants to survive drought, especially in the first months after the green roof has been installed.

Figure 6 presents the influence of antecedent dry period (ADP) as well as antecedent period elapsed from the end of rainfall causing the total saturation of models (PSTS) on the retention depth $\left(P_{r}\right)$ of examined green roof models.

The relationships presented in Figure 6 were described using linear regression equations. Regarding the results of 8 artificial rains simulated during the investigations, a strong positive linear correlation was obtained between PSTS and the depth of rainfall retained within green roof models $\left(P_{r}\right)$, at relatively high values of $R^{2}$ ranging

Table 2. Values of stormwater retention rate achieved during simulated precipitations

\begin{tabular}{|c|c|c|c|c|c|c|}
\hline \multirow{2}{*}{ Date of precipitation } & \multicolumn{7}{|c|}{ Stormwater retention rate [\%] } \\
\cline { 2 - 7 } & SHP1 & SHP2 & SHP3 & SH & S & SP \\
\hline $25 / 03 / 2019-26 / 03 / 2019$ & 64.61 & 61.91 & 69.86 & 65.45 & 67.34 & 63.15 \\
\hline $01 / 04 / 2019$ & 62.48 & 60.52 & 65.40 & 59.38 & 59.72 & 53.68 \\
\hline $08 / 04 / 2019$ & 73.14 & 73.28 & 75.36 & 66.84 & 70.84 & 69.68 \\
\hline $15 / 04 / 2019$ & 53.62 & 51.60 & 56.00 & 51,38 & 53.72 & 48.12 \\
\hline $16 / 05 / 2019$ & 43.00 & 35.75 & 42.75 & 36.50 & 29.50 & 30.90 \\
\hline $21 / 05 / 2019-23 / 052019$ & 30.52 & 32.15 & 35.40 & 36.81 & 33.66 & 32.60 \\
\hline $04 / 06 / 2019$ & 72.00 & 77.16 & 74.44 & 64.96 & 66.78 & 74.12 \\
\hline $28 / 06 / 2019$ & 85.18 & 78.48 & 79.92 & 76.88 & 77.66 & 83.40 \\
\hline $\begin{array}{c}\text { Total retention rate } \\
\text { (for 8 rain events) }\end{array}$ & 68.65 & 67.45 & 69.35 & 64.3 & 65.20 & 65.00 \\
\hline
\end{tabular}



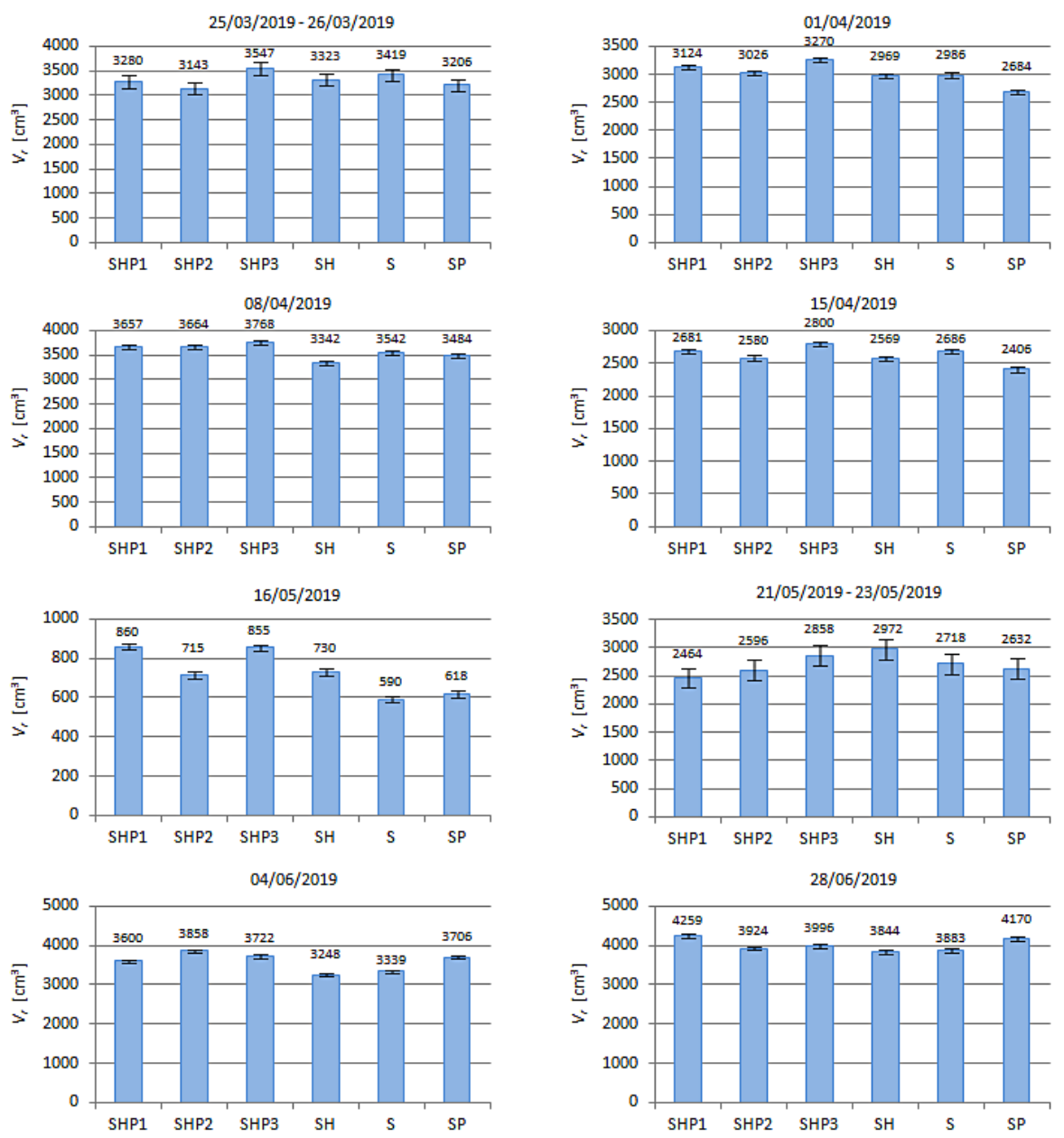

Figure 5. The volumes of water retained in the layers of models during simulated precipitations

from 0.7423 (for SP) to 0.8594 (for S). However, it should be emphasized that such good correlation resulted from the fact that the analysis involved little amount of rainfall events (only 8) which depths were relatively high, additionally 6 of 8 values of PSTS were similar, and the investigations were conducted under relatively stable weather conditions. On the other hand, the results indicate that a moderate positive linear correlation between ADP (dry period elapsed from the end of previous precipitation regardless of its depth) and the retention depth was observed at relatively low to moderate values of $R^{2}$ ranging from 0.2748 (for SHP2) to 0.3969 (for SHP1). On the basis of the results from the studies available in the literature, it can be expected that the relationship between ADP and $\left(P_{r}\right)$ would be much weaker if all natural rainfalls were included in the analysis regardless of their size (even those that did not cause runoff). In their research, Gong et al. took into account all precipitations (including light rains that do not caused the runoff) and they established that the antecedent dry periods up to
14 days had little effect on runoff retention [Gong et al., 2018]. Schulz et al. found that the retention for individual rain events showed a strong dependence on both the length of ADP and the size of the event [Schultz et al. 2018]. Baryła et al. found that ADP as well as antecedent volumetric moisture content are the parameters that determine the preceding level of moisture in the substrate. They found that the relationship between these two parameters was moderately negative, whereas ADP did not exhibit statistically significant correlation with retention [Baryła et al., 2019].

It should be emphasized that during the investigations described in the current paper, the lengths of periods elapsed from the previous total saturation PSTS obtained in the case of 6 rainfalls were relatively similar. The dates of these events were as follows: 25/03/2019-26/03/2019, 01/04/2019, 08/04/2019, 15/04/2019, 04/06/2019, and 28/06/2019. Therefore, for these 6 rainfall events, the analysis was performed which focused on examining the influence of both mean temperature and mean relative humidity prevailing 

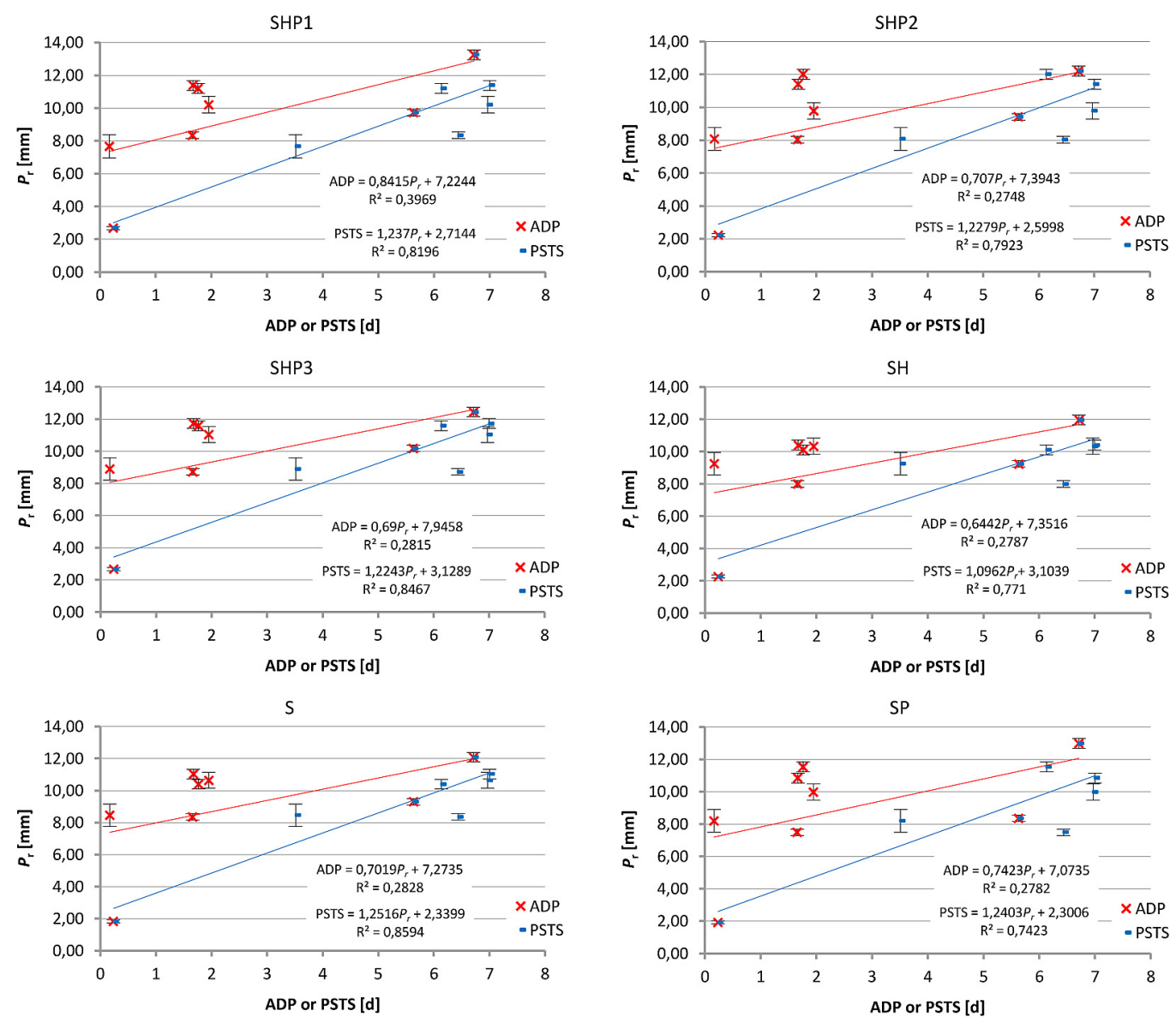

Figure 6. The influence of periods ADP and PSTS on the retention depth of green roof models

during PSTS on the retention capacity of green roof models. Table 3 presents the linear regression equations describing the dependence of the retention depth on both the mean temperature and the mean relative humidity of air.

The results presented in Table 3 show that in the case of analysed green roof models, considering only rainfall events with similar durations of PSTS, a moderate to relatively strong positive correlation was observed between $T_{m}$ and $P_{r}$. The lowest value of $R^{2}(0.5456)$ was obtained in the case of the $\mathrm{S}$ model (containing neither plants nor hydrogel), and the highest value (0.8078) was obtained in the case of the SP model (containing plants but not containing hydrogel). In turn, the results show that there was observed the weak to moderate negative correlation between $R H_{m}$ and $P_{r}$. In the case of relationship $R H_{m}$ vs. $P_{r}$ the lowest value of $R^{2}(0.1219)$ was obtained for the SH model (containing hydrogel but not containing plants), and the highest value (0.247) was achieved for the SHP1 model (containing both older hydrogel and plants).

The results presented in Table 3 may indicate that during the conducted experiments, the mean temperature as well as mean relative humidity of air could have a slightly greater effect on retention depth in the case of models covered with vegetation (due to more intensive evapotranspiration at high temperature and low relative humidity), but containing growing medium without hydrogel or containing old hydrogel with reduced efficiency. On the other hand, it should be emphasized - regarding all 8 rain events - that the best rainwater retention capacity was exhibited by the SHP3 model (containing both plants and relatively new hydrogel), but results suggest that in the case of this model, the changes of mean temperature and relative humidity affected the retention to a slightly lower degree. It should be emphasized that the analysis included only a small amount of precipitations and only averaged values of temperature and relative humidity. The extreme values of both temperature and relative humidity can strongly influence the evapotranspiration and thus the retention capacity of green roofs. In addition, other atmospheric factors may affect the retention capacity. Therefore, research should be continued taking into account other parameters, e.g. solar radiation, wind speed, etc. 
Table 3. The linear regression equations describing the dependence of retention depth $P_{r}$ on both the mean temperature $T_{m}$ and the mean relative humidity $R H_{m}$ of air prevailing during PSTS for 6 selected rainfalls (with PSTS ranged from 5.6 to 7 days)

\begin{tabular}{|c|c|c|c|c|}
\hline \multirow{2}{*}{ Model } & \multicolumn{2}{|c|}{$T_{m}$ vs. $P_{r}$} & \multicolumn{2}{c|}{$R H_{m}$ vs. $P_{r}$} \\
\cline { 2 - 5 } & Linear equation & $R^{2}$ & Linear equation & $R^{2}$ \\
\hline SHP1 & $P_{r}=0.2107\left(T_{m}\right)+8.1076$ & 0.7711 & $P_{r}=-0.1498\left(R H_{m}\right)+20.665$ & 0.247 \\
\hline SHP2 & $P_{r}=0.2054\left(T_{m}\right)+7.962$ & 0.7427 & $P_{r}=-0.1459\left(R H_{m}\right)+20.195$ & 0.2375 \\
\hline SHP3 & $P_{r}=0.1456\left(T_{m}\right)+9.1643$ & 0.5843 & $P_{r}=-0.0963\left(R H_{m}\right)+17.358$ & 0.1618 \\
\hline SH & $P_{r}=0.1455\left(T_{m}\right)+8.2283$ & 0.5885 & $P_{r}=-0.0832\left(R H_{m}\right)+15.548$ & 0.1219 \\
\hline S & $P_{r}=0.139\left(T_{m}\right)+8.5973$ & 0.5456 & $P_{r}=-0.1056\left(R H_{m}\right)+17.336$ & 0.1996 \\
\hline SP & $P_{r}=0.2625\left(T_{m}\right)+6.9843$ & 0.8078 & $P_{r}=-0.1736\left(R H_{m}\right)+31.763$ & 0.2241 \\
\hline
\end{tabular}

* where: $P_{r}(\mathrm{~mm}), T_{m}\left({ }^{\circ} \mathrm{C}\right)$, and $R H_{m}(\%)$

\section{CONCLUSIONS}

The results of investigations show that green roofs can be useful stormwater management tools. They can reduce stormwater runoff, and thus, can support the traditional sewage systems. The stormwater retention rate of examined green roof models ranged from $29.50 \%$ to $85.15 \%$.

The results indicate that in most cases the best retention capacity was exhibited by the SHP3 model, constructed in November 2017 and planted in April 2018, containing substrate amended with superabsorbent (cross-linked potassium polyacrylate). Considering 8 simulated rain events, the retention rate of SHP3 amounted to $69.35 \%$, which corresponded to the retention depth of $74.46 \mathrm{~mm}$. The remaining, similarly constructed models (SHP1 and SHP2), which were built in March 2017, in some cases retained lower amounts of water than SHP3. It should be emphasized that lower water retention capacity of the SHP1 and SHP2 models may result from the fact that they contained older hydrogel and were overgrown with older, smaller, and weaker plants, partially supplanted by mosses. The results can indicate that the efficiency of hydrogel may decrease over time.

The results of investigations conducted with use of 8 simulated precipitations indicate that there was a relatively strong positive linear correlation between retention depth and duration of period elapsed since preceding total (or substantial) saturation of green roof models (PSTS) $\left(R^{2}=0.7423 \div 0.8594\right)$. On the other hand, the results show that there was weaker positive linear correlation between retention depth and duration of antecedent dry period, elapsed since the end of last rain, regardless of its intensity (ADP).

The weather conditions i.e. air temperature and relative permeability influence the relationship between PSTS and the retention capacity of green roof models. The obtained results suggest that the effect of mean temperature on green roof retention depth may be stronger in the case of the models covered with plants.

\section{Acknowledgments}

The work was financially supported by BS/PB-400-301/19.

\section{REFERENCES}

1. Akther M., He J., Chu A., Huang J., van Duin B. 2018. A Review of Green Roof Applications for Managing Urban Stormwater in Different Climatic Zones. Sustainability, 10(8), 2864. DOI: 10.3390/ su10082864.

2. Aung T.H., Khabbaz H., Fatahi B. 2016. Parametric Study of Applied Stresses on Infiltration Modular Cells installed under Roads. Procedia Engineering, 143, 1325-1332. DOI: 10.1016/j. proeng.2016.06.154.

3. Baryła A., Karczmarczyk A., Bus A., Hewelke E. 2019. Influence of environmental factors on retention of extensive green roofs with different substrate composition. E3S Web Conf., 86, 00026. DOI: $10.1051 / \mathrm{e} 3$ sconf/20198600026.

4. Burszta-Adamiak E. 2012. Analysis of the retention capacity of green roofs. J. Water Land Dev., 16(I-IV), 3-9.

5. Czemiel-Berndtsson J. 2010. Green roof performance towards management of runoff water quantity and quality: a review. Ecol. Eng., 36, 351-360. DOI: 10.1016/j.ecoleng.2009.12.014.

6. Czemiel-Berndtsson J., Bengtsson L., Jinno K. 2009. Runoff water quality from intensive and extensive vegetated roofs. Ecol. Eng., 35, 369-380. DOI: 10.1016/j.ecoleng.2008.09.020.

7. Czemiel-Berndtsson J., Emilsson T., Bengtsson L. 2006. The influence of extensive vegetated roofs 
on runoff water quality. Sci. Total. Environ., 355, 48-63. DOI: 10.1016/j.scitotenv.2005.02.035.

8. Edwards E.C., Harter T., Fogg G.E., Washburn B., Hamad H. 2016. Assessing the effectiveness of drywells as tools for stormwater management and aquifer recharge and their groundwater contamination potential. J. Hydrol., 539, 539-553. DOI: 10.1016/j. jhydrol.2016.05.059.

9. Erickson A.J., Taguchi V.J., Gulliver J.S. 2018. The Challenge of Maintaining Stormwater Control Measures: A Synthesis of Recent Research and Practitioner Experience. Sustainability, 10, 3666. DOI: $10.3390 /$ su10103666.

10. Farrell C., Ang X.Q., Rayner J.P. 2013. Waterretention additives increase plant available water in green roof substrates. Ecol. Eng., 52, 112-118. DOI: 10.1016/j.ecoleng.2012.12.098.

11. Fletcher T.D. et al. 2015. SUDS, LID, BMPs, WSUD and more - The evolution and application of terminology surrounding urban drainage. Urban Water Journal, 12(7), 3-20. DOI: 10.1080/1573062X.2014.916314.

12. Getter K.L., Rowe D.B. 2006. The Role of Extensive Green Roofs in Sustainable Development. Hort. Science, 41(5), 1276-1285.

13. Getter K.L., Rowe D.B., Andresen J.A. 2007. Quantifying the effect of slope on extensive green roof stormwater retention. Ecol. Eng., 31, 225-231. DOI: 10.1016/j.ecoleng.2007.06.004.

14. Gong Y., Yin D., Fang X., Li J. 2018. Factors Affecting Runoff Retention Performance of Extensive Green Roofs. Water, 10, 1217, DOI: 10.3390/ w10091217.

15. Grant G. 2006. Extensive Green Roofs in London. Urban Habitats, 4(1), 51-65.

16. Hüttermann A., Orikiriza L.J.B., Agaba H. 2009. Application of superabsorbent polymers for improving the ecological chemistry of degraded or polluted lands. Clean - Soil Air Water, 37(7), 517-526. DOI: 10.1002/clen.200900048.

17. Jato-Espino D., Sillanpää N., Charlesworth S.M., Andrés-Doménech I. 2016. Coupling GIS with Stormwater Modelling for the Location
Prioritization and Hydrological Simulation of Permeable Pavements in Urban Catchments. Water, 8(10), 451. DOI: 10.3390/w8100451.

18. Lejcuś K., Śpitalniak M., Dąbrowska J. 2018. Swelling behaviour of superabsorbent polymers for soil amendment under different loads. Polymers, 10(3), 271. DOI: 10.3390/polym10030271.

19. Mentens J., Raes D., Hermy M. 2006. Green roofs as a tool for solving the rainwater runoff problem in the urbanized 21st century? Landscape Urban Plan., 2006, 77, 217-226. DOI: 10.1016/j. landurbplan.2005.02.010.

20. Mrowiec M., Ociepa E., Malmur R., Deska I. 2018. Sustainable Water Management in Cities under Climate Changes. Problems of Sustainable Development, 13(1), 133-138.

21. Ramos H.M., Pérez-Sánchez M.P., Franco A.B., López-Jiménez P.A. 2017. Urban Floods Adaptation and Sustainable Drainage Measures. Fluids, 2, 61. DOI: 10.3390/fluids2040061.

22. Savi T., Marin M., Boldrin D., Incerti G., Andri S., Nardini A. 2014. Green roofs for a drier world: Effects of hydrogel amendment on substrate and plant water status. Sci. Total Environ., 490, 467-476. DOI: 10.1016/j.scitotenv.2014.05.020.

23. Schultz I., Sailor D.J., Starry O. 2018. Effects of substrate depth and precipitation characteristics on stormwater retention by two green roofs in Portland OR. J. Hydrol. Reg. Stud., 18, 110-118. DOI: 10.1016/j.ejrh.2018.06.008.

24. USEPA. 2007. Reducing Stormwater Costs through Low Impact Development (LID) Strategies and Practices, EPA 841-F-07-006, December 2007.

25. VanWoert N.D., Rowe D.B., Andresen J.A., Rugh C.L., Fernandez R.T., Xiao L. 2005. Green Roof Stormwater Retention: Effects of Roof Surface, Slope, and Media Depth. J. Environ. Qual., 34, 1036-1044. DOI: 10.2134/jeq2004.0364.

26. Young T., Cameron D.D., Sorrill J., Edwards T., Phoenix G.K. 2014. Importance of different components of green roof substrate on plant growth and physiological performance. Urban Forestry \& Urban Greening, 13(3), 507-516. DOI: 10.1016/j. ufug.2014.04.007. 